\title{
Shock experiments on basalt-Ferric sulfate mixes and their possible relevance to the sulfide bleb clusters in large impact melts in shergottites
}

\author{
M. N. RAO (iD *1 ${ }^{1}$, L. E. NYQUIST ${ }^{2}$, P. D. ASIMOW ${ }^{3}$, D. K. ROSS ${ }^{4,5}$, S. R. SUTTON (iD ${ }^{6,7}$, \\ T. H. $\mathrm{SEE}^{8}$, C. Y. SHIH ${ }^{4}$, D. H. GARRISON ${ }^{8}$, S. J. WENTWORTH ${ }^{9}$, and J. PARK ${ }^{10}$ \\ ${ }^{1}$ SCI, Johnson Space Center, Houston, Texas 77058, USA \\ ${ }^{2}$ XI, NASA, Johnson Space Center, Houston, Texas 77058, USA \\ ${ }^{3}$ Division of Geological and Planetary Sciences, California Institute of Technology, Pasadena, California 91125, USA \\ ${ }^{4}$ Jacobs JETS, NASA, Johnson Space Center, Houston, Texas 77058, USA \\ ${ }^{5}$ UTEP-CASSMAR, El Paso, Texas 79968, USA \\ ${ }^{6}$ Department of Geophysical Sciences, University of Chicago, Chicago, Illinois 60439, USA \\ ${ }^{7}$ CARS, Argonne National Laboratory, Argonne, Illinois 60439, USA \\ ${ }^{8}$ Barrios Technology/Jacobs JETS, NASA, Johnson Space Center, Houston, Texas 77058, USA \\ ${ }^{9}$ HEPCO, Jacobs JETS, NASA Johnson Space Center, Houston, Texas 77058, USA \\ ${ }^{10}$ Kingsborough Community College, Brooklyn, New York 11235, USA \\ *Corresponding author. E-mail: sitarao@sbcglobal.net
}

(Received 29 July 2020; revision accepted 04 November 2021)

\begin{abstract}
Large impact-melt pockets in shergottites contain both Martian regolith components and sulfide/sulfite bleb clusters that yield high sulfur concentrations locally compared to bulk shergottites. The regolith may be the source of excess sulfur in the shergottite melt pockets. To explore whether shock and release of secondary Fe-sulfates trapped in host rock voids is a plausible mechanism to generate the shergottite sulfur bleb clusters, we carried out shock recovery experiments on an analog mixture of ferric sulfate and Columbia River basalt at peak pressures of 21 and $31 \mathrm{GPa}$. The recovered products from the $31 \mathrm{GPa}$ experiment show mixtures of Fe-sulfide and Fe-sulfite blebs similar to the sulfur-rich bleb clusters found in shergottite impact melts. The $21 \mathrm{GPa}$ experiment did not yield such blebs. The collapse of porosity and local high-strain shear heating in the $31 \mathrm{GPa}$ experiment presumably created high-temperature hotspots $\left(\sim 2000^{\circ} \mathrm{C}\right)$ sufficient to reduce $\mathrm{Fe}^{3+}$ to $\mathrm{Fe}^{2+}$ and to decompose sulfate to sulfite, followed by concomitant reduction to sulfide during pressure release. Our results suggest that similar processes might have transpired during shock production of sulfur-rich bleb clusters in shergottite impact melts. It is possible that very small $\mathrm{CO}$ presence in our experiments could have catalyzed the reduction process. We plan to repeat the experiments without $\mathrm{CO}$.
\end{abstract}

\section{INTRODUCTION}

Shock-induced melts, whether found in extraterrestrial (shergottites, lunar samples, cometary objects) or terrestrial (impact glasses, impact melt rocks, tektites) materials, display a variety of $\mathrm{Fe}$ - and S-bearing blebs quenched from immiscible sulfide melts (Basu, 2005; Ishii et al., 2008; Keller \& McKay, 1997; Noguchi et al., 2014;

This paper is dedicated to the memory of Kent Ross, major contributor to this work, who passed away in July 2021.
Sheffer, 2007; Sheffer \& Melosh, 2005; Sheffer et al., 2006). Some of the blebs found in lunar soil agglutinates and cometary objects contain $\mathrm{np}$ (nanophase) $\mathrm{Fe}^{0}$ (metal) particles, sometimes rimmed by FeS. By contrast, immiscible silicate, sulfide, and $\mathrm{Fe}-\mathrm{Ni}$ metal melts in terrestrial impact melts, as well as sulfur blebs in tektites and fulgurites, are principally produced from oxidized $\left(\mathrm{Fe}^{3+}\right)$ iron-bearing minerals in silicate target rocks, though they also yield some evidence for impact melting of the projectile (Hamann et al., 2018). Impact melt (IM) pockets and pods in shergottites (e.g., fig. 6 of Rao et al., 2018) 
contain excess sulfur in the form of large clusters of micrometer-sized $\mathrm{Fe}$ - and S-bearing blebs with X-ray absorption near edge spectra (XANES) below the sulfur K-edge indicating mixed sulfite and sulfide species (Rao et al., 2018; Sutton et al., 2008). Rao et al. (2018) noted that these sulfur blebs are not related to the igneous sulfides commonly found in shergottites because they yield locally sulfur abundances (up to $20 \%$ as $\mathrm{SO}_{3}$ ) far above the normal bulk sulfur abundance in shergottites, $\sim 0.5 \%$ (Gattacceca et al., 2013; Lorand et al., 2005; McSween \& Jarosewich, 1983). The blebs in shergottite IMs show large variations in $\mathrm{Ni}$ concentration, from $<1 \%$ up to $6 \%$ (Gattacceca et al., 2013). Shergottite IMs studied to date do not contain any np $\mathrm{Fe}^{0}$ particles (Rao et al., 2018; Sutton et al., 2008). This variety of observed bleb types likely reflects the range of precursor chemistry and the range of pressure-temperature-time paths of the shock and pressure release processes involved in their formation.

The shergottites - such as EETA79001, Shergotty, and Zagami - that contain $\sim \mathrm{cm}$-sized IM pockets (or pods) release large quantities of Martian atmospheric gases upon heating in vacuo (Becker \& Pepin, 1984; Bogard \& Johnson, 1983; Swindle et al., 1986; Wiens, 1988). Such IMs also preserve isotopic evidence for the entrainment of Martian regolith components, including near-surface neutron-induced excesses of ${ }^{80} \mathrm{Kr}$ from the decay of ${ }^{79} \mathrm{Br}(\mathrm{n}, \gamma){ }^{80} \mathrm{Br}$ and deficits in ${ }^{149} \mathrm{Sm}$ relative to ${ }^{150} \mathrm{Sm}$ attributed to galactic cosmic ray interactions (Hidaka et al., 2009; Rao et al., 2002, 2011). Moreover, some of these impact melts exhibit a pronounced anticorrelation trend between sulfur $\left(\right.$ as $\mathrm{SO}_{3}$ ) and $\mathrm{Si} \mathrm{(as}$ $\mathrm{SiO}_{2}$ ) (shown in fig. 2 of Rao et al., 2018) that is similar to the trend observed in soils and rocks at Gusev and Meridiani craters on Mars (Brückner et al., 2008; Rao et al., 2018). These results suggest that the precursors of the sulfur-bearing components in shergottite IMs could have been derived from the Martian regolith.

The present Martian surface environment, however, is highly oxidizing and neither sulfide nor sulfite is found commonly at the Martian rover landing sites explored to date. In fact, sulfur is found predominantly in the form of $\mathrm{Fe}$ and $\mathrm{Ca}$ sulfates in rocks and soils at Meridiani, Gusev, and Gale craters, according to both APXS and Mössbauer measurements (Bibring et al., 2007; Clark et al., 2005; Gellert et al., 2004; King \& McLennan, 2010; McAdam et al., 2014; Morris et al., 2006). These sulfates are thought to be produced by acid sulfate fluid alteration of igneous precursor minerals under oxidizing conditions (McLennan, 2012). In this context, Rao et al. (2018) proposed that the sulfur-bearing blebs in shergottite IMs were produced by shock melting of iron sulfates that had been entrained, prior to impact, into voids in porous target rocks by regolith gardening processes such as sedimentary mixing, hydrothermal transport, or aeolian activity (Greeley et al., 2004). Such sulfate might be present in the form of amorphous precursors of minerals such as melanterite and jarosite (ubiquitously present near the Martian surface). Since amorphous sulfate-bearing material is preferentially associated with porosity, the proposed mechanism appeals to the uniquely high temperatures generated in the vicinity of collapsing pores upon shock consolidation. Amorphous materials in pores would be exposed to temperatures $\left(>2000^{\circ} \mathrm{C}\right)$ sufficient to cause melting under pressure, while nearby crystalline materials might remain relatively unaffected (Beck et al., 2007; Gillet et al., 2000; Sharp \& DeCarli, 2006). Ferric sulfate in these high-temperature melts would likely decompose to ferrous sulfite and then could be partly reduced to sulfide during pressure release from the hightemperature shock state (Melosh \& Artemieva, 2004; Schrader et al., 2016; Sheffer, 2007; Sheffer \& Melosh, 2005; Sheffer et al., 2006), producing a reduced sulfurrich immiscible melt. Upon quenching, the immiscible melt would be dispersed, yielding innumerable micrometer-sized sulfur blebs.

Although considerable information is available regarding high-temperature and -pressure shock effects on meteoritic and lunar mineral assemblages, attention has mostly been directed toward primary rock-forming minerals such as olivine, pyroxene, and feldspar. Comparatively fewer results are available concerning shock effects in secondary and accessory minerals such as S-bearing constituents. Shock processing due to micrometeorite impact on $\mathrm{Fe}_{(1-x)} \mathrm{S}$ (pyrrhotite) in lunar soils and agglutinates has been studied in detail by Keller and McKay (1997), Ishii et al. (2008), and Basu (2005). Similar studies were also performed on pyrrhotite in interplanetary and cometary dust particles from Stardust, Itokawa, and comet 81P/Wild 2 (Ishii et al., 2008; Keller \& Berger, 2014; Noguchi et al., 2014). Experimental shock results on oxidized accessory phases such as ferric sulfate are lacking, although shock decomposition thresholds for $\mathrm{Ca}$ - and $\mathrm{Mg}$-sulfates have been studied due to their significance as sources of atmospheric $\mathrm{SO}_{2}$ in the Chicxulub event (Chen et al., 1994; Gupta et al., 2001; Ivanov \& Deutsch, 2002; Zhang \& Sekine, 2007).

To examine the validity of our proposition that the sulfur-bearing bleb clusters found in impact melts in shergottites were likely produced by shock melting of iron sulfate followed by reduction to sulfide during release to low pressure, we carried out laboratory shock experiments on test charges of Columbia River Basalt (CRB) mixed with ferric sulfate $\left(\mathrm{Fe}_{2}\left(\mathrm{SO}_{4}\right)_{3} \cdot 9 \mathrm{H}_{2} \mathrm{O}\right)$ in steel chambers. One experiment, at the Lindhurst Laboratory of Experimental Geophysics at Caltech, 
reached peak pressure of $31 \mathrm{GPa}$ and featured a nominal amount of $\mathrm{CO}$ gas that was bled into the pore space after adsorbed moisture and air were pumped out of the experimental charge. The other experiment, at the Experimental Impact Laboratory at NASA Johnson Space Center (JSC), reached peak pressure of $21 \mathrm{GPa}$ and had air in the initial pore space.

The peak pressure and temperature conditions experienced by shergottites can be estimated by comparing their mineral assemblages to experiments, but both dynamic and static experiments have critical shortcomings as tools for such calibration (Tomioka \& Miyahara, 2017). Shock wave experiments can only maintain high-pressure conditions for durations on the order of microseconds (Gillet et al., 2007; Sharp \& DeCarli, 2006) whereas natural impact events may be able to support high pressure for many seconds (Beck et al., 2005; Bowling et al., 2020; Gillet \& El Goresy, 2013). Furthermore, pressure and temperature paths in shock recovery experiments are typically inferred from ancillary data rather than directly measured. By contrast, static high-pressure, high-temperature experiments hold well-defined and measured $(P, T)$ conditions for durations typically much longer than impact events (minutes to hours), but they lack the dynamic, turbulent mixing processes that are characteristic of impact melts just behind a shock front. Here, we briefly review pressure estimates based on olivine and feldspar in melt veins in shergottites, which guided our choice of experimental pressure. Miyahara et al. (2011) found the assemblage of bridgmanite and ferropericlase in olivine-phyric shergottite $\mathrm{DaG} 735$, suggesting pressure in excess of $\sim 25 \mathrm{GPa}$ for this shergottite. Olivine-group polymorphs and their decomposition products suggest pressures in the 23-25 GPa range in most shergottites (Chen et al., 1996; El Goresy et al., 2013; Malavergne et al., 2001; Tomioka \& Miyahara, 2017). The ubiquitous conversion of matrix plagioclase to amorphous maskelynite in shergottites is thought to place a minimum pressure in the neighborhood of $20 \mathrm{GPa}$ for matrix regions, but transformations of feldspars in the melt pockets and veins of shergottites suggest higher pressure. Langenhorst and Poirier (2000) suggested a liquidus assemblage of stishovite plus liebermannite in shock melt veins in Zagami, associated with lingunite. In similar veins in Zagami, Beck et al. (2007) found another liquidus assemblage of hexagonal $\left(\mathrm{Ca}_{x} \mathrm{Na}_{1-x}\right)$ $\mathrm{Al}_{3+x} \mathrm{Si}_{3-x} \mathrm{O}_{11}$ (CAS) and stishovite. In static experiments at $1300 \mathrm{~K}$, liebermannite requires pressure above $12 \mathrm{GPa}$, lingunite requires $21-24 \mathrm{GPa}$ (El Goresy et al., 2013; Yagi et al., 1994). CAS and stishovite only coexist in a narrow range near $22 \mathrm{GPa}$ at $2000-2200^{\circ} \mathrm{C}$ (Akaogi et al., 2010). All these results suggest that, despite some variability in peak pressure and the possibility of $P-T$ evolution during the shock event, $P \sim 20 \mathrm{GPa}$ is a reasonable lower limit and $P \sim 30 \mathrm{GPa}$ is a reasonable upper limit. We do not have independent control of temperature in our shock recovery experiments, but the development of impact melt pockets suggests that near-liquidus temperatures, $\geq 2000{ }^{\circ} \mathrm{C}$, were transiently achieved in collapsing pore space.

The recovered sample charges were analyzed by field-emission scanning electron microscopy (FE-SEM) and electron probe microanalyzer (EPMA). The results of these analyses are presented here (preliminary results were reported by Rao et al., 2019). We show that bleb clusters resembling those in shergottite impact melts can in fact be produced by shock melting, decomposition, and reduction of ferric sulfate. We suggest that this mechanism is a viable path to shergottite IM blebs, whereas shock melting of $\mathrm{Fe}_{(1-x)} \mathrm{S}$ (pyrrhotite) is not.

\section{EXPERIMENTAL AND ANALYTICAL METHODS}

\section{GPa Shock Recovery Experiment at Caltech}

About $50 \mathrm{mg}$ of CRB powder with a typical grain size of $\sim 65 \mu \mathrm{m}$ plus hydrated ferric sulfate $\left(\mathrm{Fe}_{2}\left[\mathrm{SO}_{4}\right]_{3} \cdot 9 \mathrm{H}_{2} \mathrm{O}\right)$ in the form of powder and chips up to $\sim 1 \mathrm{~mm}$ were mixed and heated to $110^{\circ} \mathrm{C}$ in vacuum for a few hours (to remove adsorbed moisture) at the Lindhurst Laboratory for Experimental Geophysics at Caltech (Fig. 1a). This mix was pressed at 2200 psi into a pellet of $5 \mathrm{~mm}$ diameter and $1.17 \mathrm{~mm}$ thick having an estimated porosity of $28 \%$. The pellet was loaded into the cavity of a stainless steel (SS) 304 sample retainer within a vented sample housing. The target assembly was placed in the target chamber of a $20 \mathrm{~mm}$ bore single stage gun, pumped to vacuum through the vent port and exposed to laboratory grade $\mathrm{CO}$. The pore space in the sample contained $\sim 0.8$ bars of $\mathrm{CO}$ gas at ambient temperature. A $2.5 \mathrm{~mm}$ thick SS 304 flyer was launched at a measured pre-impact velocity of $2.04 \mathrm{~km}$ $\mathrm{s}^{-1}$ and impacted the surface of the sample holder, generating a shock wave with a first shock state in the sample estimated at $15 \mathrm{GPa}$ and $1540 \mathrm{~K}$ and a reshock to $\sim 31 \mathrm{GPa}$ at $3500 \mathrm{~K}$ experienced by the rear portion of the sample volume. Pressure was estimated using a Hugoniot derived from Caltech experiments on Saddleback Basalt mixed with the Hugoniot of ferric sulfate using a mass-averaging procedure and an estimated Grüneisen parameter to account for porosity (initial density $2025 \mathrm{~kg} \mathrm{~m}^{-3}$, initial bulk sound speed $1968 \mathrm{~m} \mathrm{~s}^{-1}$, Hugoniot slope $s=1.42$, and Grüneisen $\gamma=1.37$ ). In much of the literature on shock recovery experiments, this shot would be reported using the "full 

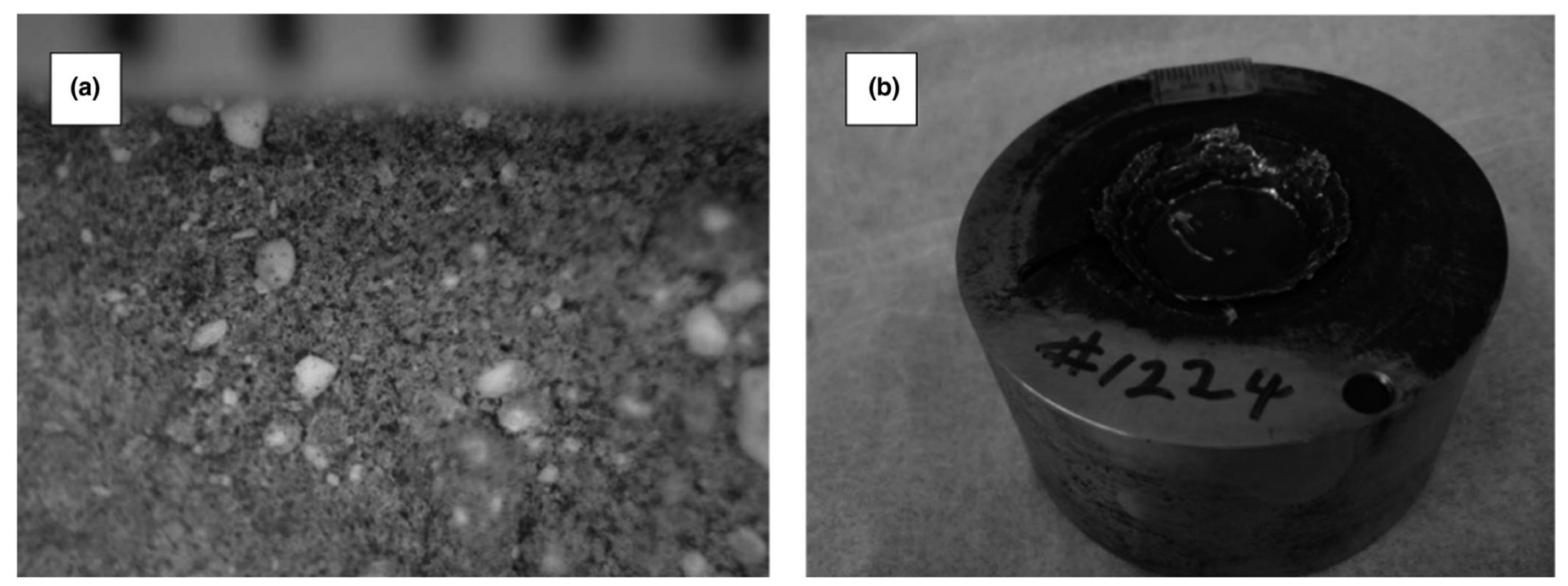

Fig. 1. Experimental setup.a) Mixture of powdered Columbia River Basalt and ferric sulfate (white chips) prior to pressing into pellet for loading into Caltech sample recovery chamber.b) Post-shot photograph of recovery target with visible crater and intact chamber.

ring-up" or reverberation pressure of $49 \mathrm{GPa}$; however, given the thickness of the sample chamber relative to the flyer plate, full reverberation did not occur in this experiment. The recovered sample holder had a welldefined crater with no evidence for failure of the sample chamber or loss of sample (Fig. 1b).

The chamber was sawn open and one half of the shocked sample was impregnated with epoxy (preserving in situ spatial distribution of the reaction products) and machined to fit into the FE-SEM sample holder at JSC. The top surface of the sample was then gently polished to remove epoxy and expose the shocked sample for FE-SEM and EPMA measurements at JSC.

\section{GPa Shock Recovery Experiment at JSC}

The JSC experiment used the Flat-Plate Accelerator facility, also a $20 \mathrm{~mm}$ caliber horizontal powder propellant gun. The target assembly consisted of a disk pressed from the same mix of CRB powder and ferric sulfate chips as the Caltech experiment, moderately pressed into a pellet with estimated porosity of $28 \%$. The pellet was loaded into a $9 \mathrm{~mm}$ diameter and $0.8 \mathrm{~mm}$ deep SS sample holder. The target holder was then loaded into an SS container capsule placed in the EIL GUN chamber facility and a flat 304 SS flyer plate was launched at $1.8 \mathrm{~km} \mathrm{~s}^{-1}$ into a metallic jacket that houses the target assembly. A planar shock wave of known amplitude was generated, producing an estimated 21 GPa peak shock pressure (See et al., 2001). In this case, the very shallow sample chamber allowed for multiple shock reverberations and it is reasonable to conclude that the entire sample experienced the full ring-up pressure. The shocked sample charge was subsequently recovered by machining to open the SS capsule and prepared into a thin section for petrographic and FESEM studies. Note that the CRB plus ferric sulfate mixed charges shocked at 21 and $31 \mathrm{GPa}$ are aliquots of the same sample mix. The only difference between the two is that the Caltech $31 \mathrm{GPa}$ target porosity was exposed to CO prior to shock loading whereas the JSC $21 \mathrm{GPa}$ target had ordinary air in the pores.

\section{FE-SEM, EPMA, and Fe K-XANES Methods}

\section{FE-SEM}

The field emission scanning electron microscope model JEOL $7600 \mathrm{~F}$ at JSC was used for studying the polished thin sections of recovered shock experiments with standard operating conditions at $15 \mathrm{kV}$ accelerating potential for backscattered electron imaging (BEI) and energy-dispersive X-ray spectrometry (EDS). Both secondary (SEM) and backscattered electron (BSE) imaging modes were used. X-ray spectrometry data were obtained using IXRF and Thermo Electron EDS systems attached to the FE-SEM. Qualitative major element compositions of minerals were determined at 10 or $15 \mathrm{KeV}$ with this system (Ross et al., 2011; Wentworth et al., 2005) and are reported normalized to 100 atomic $\%$.

\section{EPMA}

Polished thin sections were analyzed using a Cameca SX100 microbeam automated electron microprobe equipped with standard Cameca instrument controls and PAP matrix correction software. Standard analytical methods and calibration procedures were used at $15 \mathrm{kV}$ accelerating potential and $20 \mathrm{nA}$ beam 
current (except for phosphates and glasses where a defocused beam $[20 \mu \mathrm{m}]$ of $10 \mathrm{nA}$ was employed). Typical dwell times on the element peaks are 10-30 s. Backgrounds were similarly checked. The following standards were used in the analysis: Marjahlati olivine is used for $\mathrm{Fe}$ in olivine; diopside for $\mathrm{Si}, \mathrm{Ca}$, and $\mathrm{Mg}$ in pyroxene; orthoclase for $\mathrm{K}$; and Hawk Mountain oligoclase for $\mathrm{Na}$ and $\mathrm{Al}$. Chromite standard was used for $\mathrm{Cr}, \mathrm{Al}, \mathrm{Fe}$, and $\mathrm{Mg}$ for the $\mathrm{Fe}$, $\mathrm{Ti}$, and $\mathrm{Cr}$ oxides. Sulfides were analyzed using Canyon Diablo troilite standard and a pyrite metal block for $\mathrm{S}$ and $\mathrm{Fe}$ and pentlandite for $\mathrm{Ni}$. Rutile was used for $\mathrm{Ti}$, Durango apatite for $\mathrm{P}$, and tugtupite for $\mathrm{Cl}$. Data are reported normalized to $100 \%$ as the samples display variable amounts of water loss (Rao et al., 1999; Wentworth et al., 2005).

\section{Fe K-XANES}

The Fe K-edge XANES measurements were carried out at the beamline 2-ID-B of the Advanced Photon Source (APS) at Argonne National Laboratory, Argonne, IL (University of Chicago) equipped with an intermediate energy scanning X-ray microscope (SXM) using standard procedures described in Newvile et al. (1998), Sutton et al. (2008), Head et al. (2018), and Rao et al. (2018).

\section{RESULTS}

The sulfur content of CRB is low $(0.05-0.2 \mathrm{wt} \% \mathrm{~S})$. The sample charge consists of CRB dry powder mixed with clumps of ferric sulfate in an $\sim 2: 1$ overall proportion (Fig. 1a). The recovered charge from the 21 GPa experiment showed very few blebs whereas the recovered sample from the $31 \mathrm{GPa}$ experiment yielded abundant clusters of S-bearing blebs in impact melt pockets. The sulfur-bearing blebs in this experiment are of two kinds: one variety is the "sulfide" blebs that are usually round and have metallic luster and bright reflectivity. The other type is the "sulfite" or "mixed sulfite-sulfide" blebs, which appear dull in reflected light and display a distinctly nonmetallic appearance. The second type occurs in both rounded and elongated shapes. Typical pictures of these blebs are shown in Fig. 2 and the FE-SEM EDS spectra are given in Fig. 3.

\section{GPa Shock Experiment (Caltech)}

The texture of the recovered charge from the $31 \mathrm{GPa}$ shock experiment is nonuniform. Some areas near the front half of the capsule, which experienced only one shock wave passage and a peak pressure of $15 \mathrm{GPa}$ before arrival of a release wave, showed only a few sulfur-bearing blebs situated in a large amount of unmelted ferric sulfate and CRB particulates. Other areas, toward the back half of the sample that experienced reshock to $31 \mathrm{GPa}$, contain numerous isolated pockets of material quenched from melt and are filled with clusters of micrometer-sized sulfur-bearing blebs (Fig. 2). The spatial distribution of molten material in the sample suggests that the shock wave propagated nonuniformly in the target charge, leading to extensive melting in certain portions of the sample mix while other areas remained unmelted. This is partly due to the multiple shocks generated by the target chamber geometry and also partly due to inhomogeneous distribution of porosity in the starting material. A similar result was obtained by Schaal et al. (1979), whose experimental shock melting of granulated lunar basalt $75035(45-75 \mu \mathrm{m}$ grain size and $28 \%$ porosity) at $50 \mathrm{GPa}$ (it is unclear if this is a hypothetical reverberation pressure or a true peak pressure) transformed only $\sim 35 \%$ of the parental material into impact melt glass. We suspect that the small number of blebs found in the front half of the sample was physically injected from the back half along shear planes.
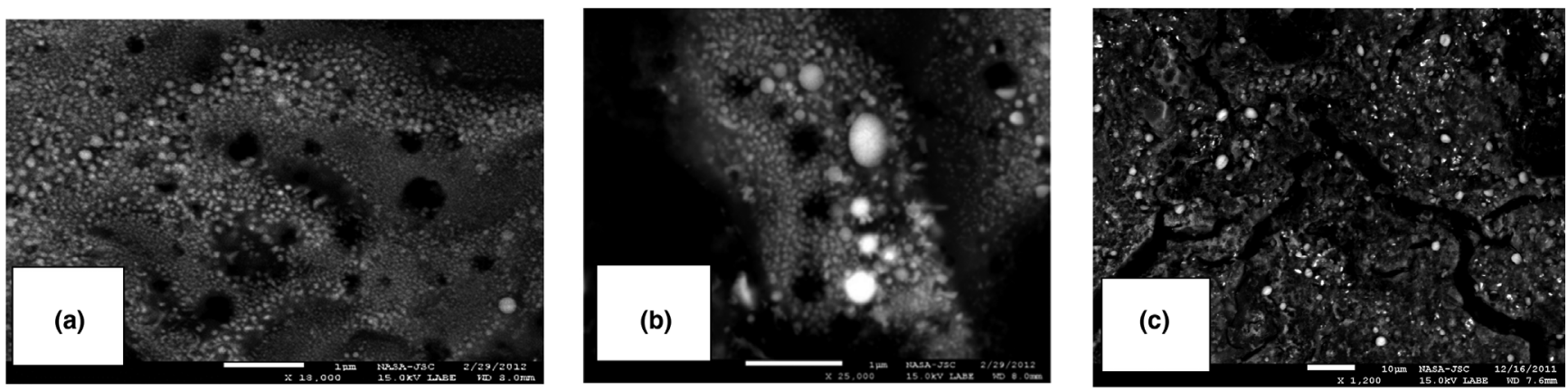

Fig. 2. Backscattered electron (BSE) images of impact melts in the $31 \mathrm{GPa}$ experiment containing abundant sulfur-rich blebs (whitish semicircular spots: (a) typical area consisting of numerous sulfide and sulfite blebs; (b) sulfite-sulfide bleb mixtures in one area with at high magnification; (c) another area; note some high-contrast spots here are titanomagnetites. 

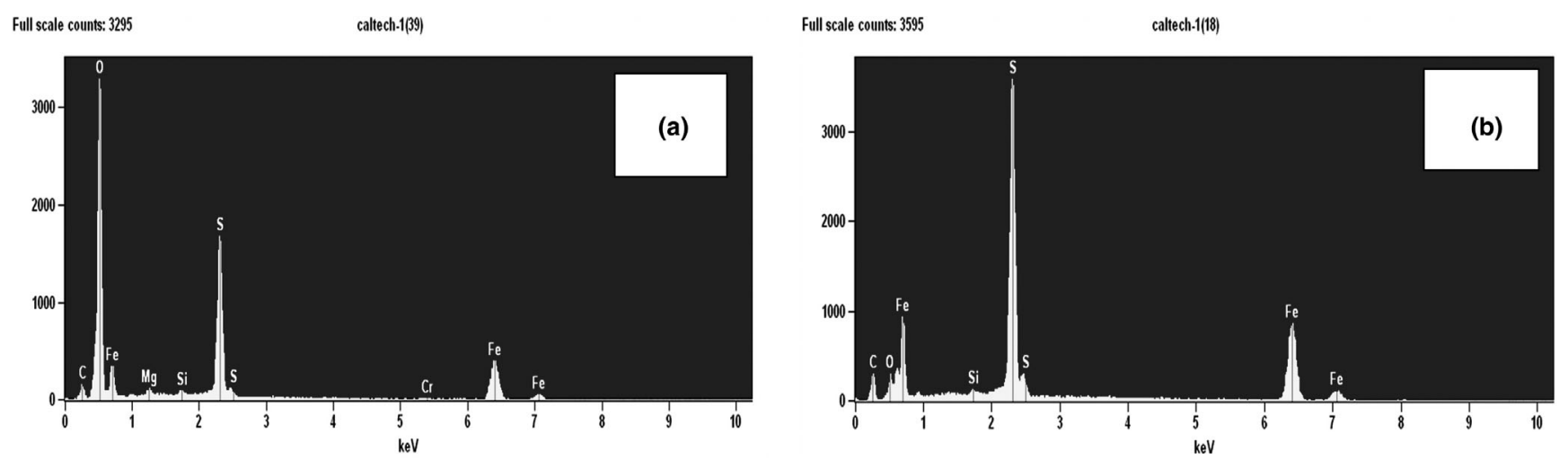

Fig. 3. Energy-dispersive X-ray (EDS) spectra of typical sulfur-rich blebs in the 31 GPa experiment: (a) EDS spectrum of a typical sulfite bleb (spherical shape) formed from a immiscible fluid on melting of crystalline Fe-sulfate grains in CRB + sulfate sample charge note the large oxygen peak. A similar peak with slightly higher peak height for oxygen was obtained for unmolten ferric sulfate crystal in the sample mix. b) A typical sulfide bleb showing metallic luster, note the near-absence of detectable oxygen. Typical EDS spectrum of Fe-sulfide blebs in the shocked sample is shown here.

The sulfur blebs found in shock-melted parts of the $31 \mathrm{GPa}$ experimental charge are of two types. Blebs of rounded to elongated shape that display dull reflectivity in optical light yield EDS spectra showing large peaks for $\mathrm{O}, \mathrm{Fe}$, and $\mathrm{S}$ (Fig. 3a). We semiquantitatively determined the $\mathrm{Fe} / \mathrm{S}$ (atomic) ratios in these blebs and they yielded values ranging from $\sim 1.02$ to $\sim 1.3$. Such stoichiometry is inconsistent with ferric sulfate $(\mathrm{Fe} / \mathrm{S}=$ $0.67)$, pyrite $(\mathrm{Fe} / \mathrm{S}=0.5)$, or pyrrhotite $(\mathrm{Fe} / \mathrm{S} \sim 0.92)$ but is consistent with either ferrous sulfite or ferrous sulfide. We found similar $\mathrm{Fe} / \mathrm{S}$ values in the natural bleb clusters in impact melt sample \#507 in EETA79001, Lith B. We tentatively interpret these blebs to be Fe-sulfite (the starting sulfate material does not form rounded blebs). More importantly, the $\mathrm{S}$ K-edge XANES spectra of the sulfur blebs in this sample show dominant peaks at $2478 \mathrm{eV}$, the energy associated with sulfite species (Fleet et al., 2005) with only minor peaks at $2470 \mathrm{eV}$, the energy typical of sulfide species (Fleet et al., 2005), and no sulfate peak. The compositional and spectroscopic results together indicate that these blebs likely consist of ferrous sulfite, $\mathrm{Fe}\left(\mathrm{SO}_{3}\right)$, presumably formed by decomposition and reduction of ferric sulfate to ferrous sulfite. Sulfate melt readily dissolves in and mixes with molten silicates in the shock state, whereas sulfite melt becomes immiscible during cooling and decompression, exsolving to form blebs dispersed in silicate glass in the quenched product.

There is another group of rounded blebs in the 31 GPa recovered charge that display metallic luster and high optical reflectivity. The EDS spectra of these blebs show $\mathrm{Fe}$ and $\mathrm{S}$ peaks only (negligible $\mathrm{O}$ peaks) and yield $\mathrm{Fe} / \mathrm{S}$ (atomic) ratios of $0.9-0.93$ (Fig. 3b). This result suggests that these metallic blebs consist of $\mathrm{Fe}_{(1-x)} \mathrm{S}$ (pyrrhotite-like) material. Lorand et al. (2005) and Gattacceca et al. (2013) showed that the igneous sulfides in shergottites yield $\mathrm{Fe} / \mathrm{S}$ (atomic) ratios of 0.9 0.93. However, the $\mathrm{CRB}+$ ferric sulfate starting material in this experiment contained no igneous pyrrhotite. Instead, the presence of pyrrhotite-like blebs indicates that decomposition and further reduction, from sulfate through sulfite and all the way to sulfide, occur during shock melting and pressure release.

The initial pore space in the $31 \mathrm{GPa}$ experimental charge contained $\mathrm{CO}$ that was introduced in order to avoid the oxidizing power of terrestrial atmospheric $\mathrm{O}_{2}$. In retrospect, this was a poor choice in that reduction by $\mathrm{CO}$ offers an apparent explanation for our results that would not apply to Mars. However, we argue that $\mathrm{CO}$ played a negligible role as a reducing agent for the $\mathrm{Fe}$ and $\mathrm{S}$ in the charge, on the basis of the following mass balance. The porosity (or volume fraction of $\mathrm{CO}$ gas) in the starting material was $28 \%$. The density of $\mathrm{CO}$ gas at the initial conditions $(0.8$ bar and $298 \mathrm{~K})$ is $0.916 \mathrm{~kg} \mathrm{~m}^{-3}$ whereas the density of the solid (CRB $+\mathrm{Fe}$ sulfate) starting mix is $2025 \mathrm{~kg} \mathrm{~m}^{-3}$. This corresponds to a mass fraction of $\mathrm{CO}$ gas of 0.00018 or 0.0063 moles of oxygen acceptor capacity per $\mathrm{kg}$ of bulk sample. Conservatively, assuming that we produced only ferrous sulfite (i.e., neglecting further reduction to sulfide) by reduction of ferric sulfate, we find that one could produce at most 0.0031 moles of $\mathrm{Fe}\left(\mathrm{SO}_{3}\right)$ per $\mathrm{kg}$ of bulk sample. This corresponds to a maximum mass fraction yield of ferrous sulfite of 0.00043 ( $\mathrm{kg} \mathrm{Fe}$ sulfite $/ \mathrm{kg}$ bulk sample) or a volume fraction of ferrous sulfite blebs of 0.0006. The BSE images of our sample show an S-bleb volume fraction much greater than 1 part in $10^{3}$. Hence, the autoreduction mechanisms we discuss below are required; if the $\mathrm{Fe}$ and $\mathrm{S}$ did react with the $\mathrm{CO}$ gas, this could be at most a minor contribution to their 
reduction. However, there remains the possibility that even this small amount of $\mathrm{CO}$ might have somehow nucleated or catalyzed the reduction process, which then became self-supporting. Hence, this issue remains an open question at this time. We intend to follow this report with a further test: a shock experiment replicating the $31 \mathrm{GPa}$ shock at Caltech but with lowpressure $\mathrm{CO}_{2}$ in the pore space (without $\mathrm{CO}$ ).

\section{GPa Shock Experiment (JSC)}

In the $21 \mathrm{GPa}$ experiment, however, the areas examined in the polished thin section prepared from the recovered charge do not show any evidence of sulfide or sulfite bleb formation as a result of shock melting and reduction. However, there are several amorphous regions suggesting incipient melting (Fig. 4a). These amorphous areas display a typical cracking pattern consistent with differential thermal contraction. Such cracks are absent from the impact melt areas of the 31 GPa shock experiment; they may indicate that the local hotspots in the $21 \mathrm{GPa}$ experiment that underwent incipient melting subsequently experienced larger thermal contraction than colder surrounding areas, resulting in tensile stresses. The dominant lowtemperature minerals present in the sample mix are apatite (from the CRB powder) and the added hydrated ferric sulfate. The EDS spectra of most of these amorphous regions display the prominent peaks of $\mathrm{Fe}$, $\mathrm{O}, \mathrm{S}$, and $\mathrm{P}$ that indicate the presence of sulfate and phosphate (Fig. 4b). Measurable peaks of $\mathrm{Na}, \mathrm{Mg}, \mathrm{Al}$, $\mathrm{Si}, \mathrm{K}$, and $\mathrm{Ca}$ are also present. These complex multielement spectra do not fit the stoichiometry of pure mineral phases; they are instead consistent with the flexible chemical compositions of melts and glasses. We suggest that apatite and iron sulfate preferentially dissolved into a granitoid minimum melt formed by low-degree incipient melting. Some amorphous regions lack the prominent $\mathrm{P}$ peak; this is consistent with the sparse distribution of apatite in the starting material and the limited time available for mixing across the charge. The low-degree melts quenched to amorphous material and there is no indication of immiscible melt separation in these regions; S-rich blebs are not observed. The absence of observable reduction of sulfate in this experiment may be attributed to the low shock temperature achieved or the low degree of melting reached. We also note the absence of $\mathrm{CO}$ gas in the pore space of this sample, but thermodynamic calculations showing reduction upon release of chemically closed systems from high shock temperatures (Sheffer, 2007) suggest that an external reductant is probably not an essential prerequisite to sulfide formation in these experiments and the above argument from stoichiometry shows that the presence of $\mathrm{CO}$ in the $31 \mathrm{GPa}$ experiment does not by itself explain the difference between the two outcomes. We tentatively conclude that $21 \mathrm{GPa}$ is insufficient peak shock pressure to match the observations of shergottite impact melts.

\section{DISCUSSION}

\section{Reduction During Shock Release}

The process of reduction of $\mathrm{Fe}$ and $\mathrm{S}$ in a shock melt that accompanies decompression and release from the shock state is referred to as "reduction due to isentropic cooling" (Melosh \& Artemieva, 2004; Sheffer, 2007; Sheffer \& Melosh, 2005). This type of $\mathrm{Fe}$ reduction is known to occur during the formation of
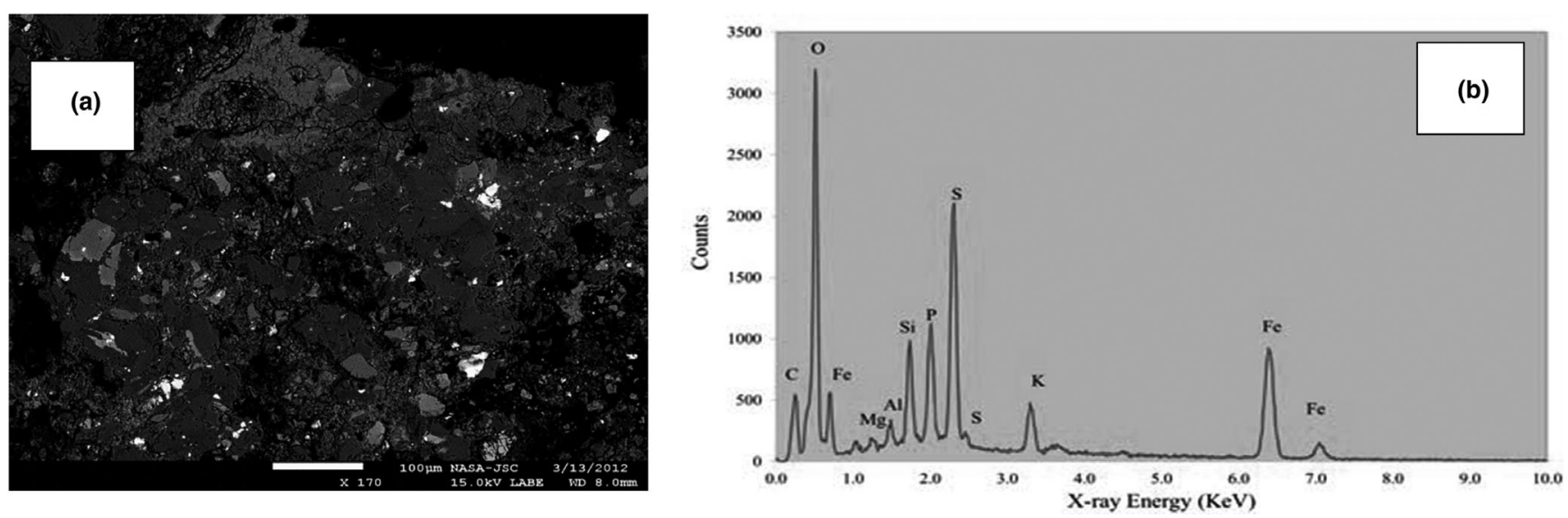

Fig. 4. Incipiently molten region in the $21 \mathrm{GPa}$ charge: (a) BSE image; (b) EDS spectrum showing O, P, S, Ca, and Fe peaks attributed to melting of apatite and ferric sulfate, as well as $\mathrm{Na}, \mathrm{Mg}, \mathrm{Al}, \mathrm{Si}$, and $\mathrm{K}$ peaks attributed to a granitic minimum melt component produced by incipient melting of the bulk mixture. 
lunar agglutinates due to micrometeorite impacts and on Earth during the formation of tektites and moldavites by asteroid impacts. Note that, in other contexts, the recovery from a high-pressure shock state is called "isentropic release." Indeed, "isentropic cooling" may sound somewhat contradictory, since "cooling" suggests removal of heat, which implies a decrease in entropy. However, isentropic pressure release is indeed accompanied by decreasing temperature, which is the sense in which "cooling" was used by Melosh and Artemieva (2004). We retain this usage from the cited references to describe the coupled path of pressure and temperature decrease at roughly constant entropy.

The complete thermodynamic path of a strong shock event can be described in several stages. The passage of a shock wave causes an irreversible jump in pressure, temperature, and entropy. Strong shock compression, especially in porous starting materials that undergo large irreversible changes in volume, may result in shock temperatures of several thousand Kelvin that leads to melting and even incipient vaporization. After some time in this shock state (for a supported shock), pressure is typically released by the passage of a rarefaction wave. Rarefactions are not shocks and they are approximated as isentropic acoustic waves, following constant entropy paths toward lower pressure and somewhat lower temperature (Beck et al., 2007; Gillet et al., 2007; Sharp \& DeCarli, 2006). Vapor production is likely during release, as the pressure drops below the critical point while temperature remains elevated compared to the starting condition (Davies et al., 2020). Molecules in the high-temperature vapor phase easily decompose or ionize and electron exchange between the liquid and vapor phases may occur. Such complex nonequilibrium chemical reactions at the vapor-liquid interface continue until cooling reaches a blocking temperature where exchange slows and the phases become decoupled (Melosh \& Artemieva, 2004; Sheffer et al., 2006). This leaves the shock melt (at the time it transforms into glass) with a different net oxidation state than the starting material (Rao et al., 2018). Even at equilibrium (equal oxygen fugacity in both phases), the vapor becomes increasingly enriched in oxygen relative to the liquid, leaving the liquid progressively more oxygen depleted. Disequilibrium enhances the effect. Continuous degassing as pressure drops and volatile solubility decreases leads to continuous increase in the intensity of oxygen transfer to the vapor and reduction of the melt (Sheffer \& Melosh, 2005).

Evidently an open system process is necessary to explain our experimental observation of the production of ferrous sulfite and sulfide from initial ferric sulfate.
Both iron and sulfur are reduced during this process and there is no obvious reducing agent that undergoes a complementary oxidation (the amount of $\mathrm{CO}$ present in the $31 \mathrm{GPa}$ experiment is very small and not sufficient). It is likely that the vapor phase acted as this reducing agent, taking up oxygen from the melt while the melt and vapor were open to mass and charge exchange. The experimental results suggest that a similar autoreduction may plausibly be invoked to explain the production of sulfide and sulfite in shergottite impact melts from initially oxidized sulfur as $\mathrm{Fe}$ sulfate from a Martian regolith component.

\section{What Happens When $\mathrm{Fe}_{(1-x)} \mathrm{S}$ (Pyrrhotite) Is Shock Heated at High Temperatures and Pressures by Impact in Extraterrestrial Samples?}

Although a small amount of $\mathrm{FeS}$ is present in the CRB starting material, its mass fraction is insufficient to be the source of the S-blebs in the $31 \mathrm{GPa}$ run product. Moreover, numerous observations of Martian meteorites and other samples show that pyrrhotite cannot be the source of the abundant sulfite-sulfide blebs observed in shergottite impact melts. When $\mathrm{Fe}_{(1-x)} \mathrm{S}$ (pyrrhotite) in reduced extraterrestrial targets is shock heated, it is likely to dissociate into $\mathrm{Fe}^{2+}$ and $\mathrm{S}^{2-}$ in the impact melt. If the release path follows reducing conditions, the $\mathrm{Fe}^{2+}$ will be reduced to np (nanophase) $\mathrm{Fe}^{0}$ (metal), as observed in lunar agglutinates. However, the sulfur is already fully reduced. In the form of sulfide ion $\left(\mathrm{S}^{2-}\right)$, sulfur is relatively immobile (Wilke et al., 2008), has low vapor pressure, and is retained by the melt. However, sulfide may react with cations to form solid sulfide species (Rao et al., 2018), including FeS (troilite), $\mathrm{Fe}_{(1-x)} \mathrm{S}$ (pyrrhotite), or $\mathrm{FeS}_{2}$ (pyrite), depending on sulfur fugacity (as found, e.g., in Tissint; see Gattacceca et al., 2013; Rao et al., 2018). Recently, Ohtaki et al. (2019) studied the np $\mathrm{Fe}^{0}$ particles in lunar soils using high-resolution secondary ion mass spectrometry (nano-SIMS) and transmission electron microscopy (TEM) and found that a significant number of the np $\mathrm{Fe}^{0}$ particles are rimmed by FeS. Ohtaki et al. (2019) concluded that these objects formed by impact melting of pyrrhotite in a reducing environment. Ishii et al. (2008) found similar particles having nm-thick sulfide rims surrounding $10-15 \mathrm{~nm} \mathrm{np} \mathrm{Fe}^{0}$ metal cores in returned dust samples from comet $81 \mathrm{P} /$ Wild 2 . Moreover, experimental hypervelocity implantation of nearly spherical micrometer-sized pyrrhotite particles into an aerogel target at $6 \mathrm{~km} \mathrm{~s}^{-1}$ resulted in abundant nm-scale sulfide-rimmed $\mathrm{Fe}$ metal particles similar to those observed in Stardust material (Ishii et al., 2008). The spherical shape suggests that these particles are derived from immiscible $\mathrm{FeS}$ melt droplets that partly 


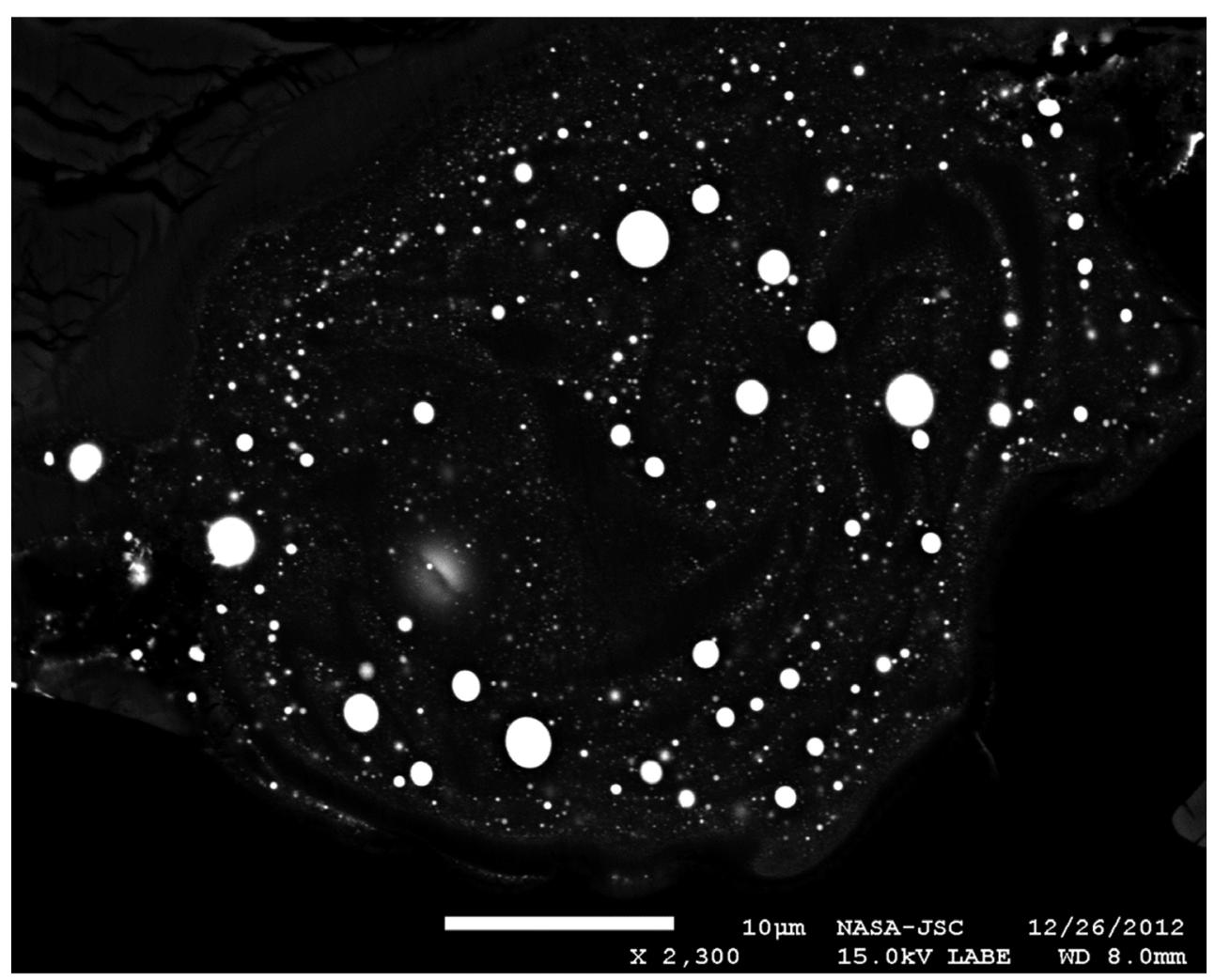

Fig. 5. An example of reduced sulfur-bearing blebs in impact melt in a shergottite: "swirl" of sulfide-sulfite blebs in Tissint impact melt. Similar structures are also found in impact melts recovered in the $31 \mathrm{GPa}$ Caltech experiment.

decomposed and dispersed before quenching with an $\mathrm{Fe}_{(1-x)} \mathrm{S}$ rim (Noguchi et al., 2014). The formation of "swirl" patterns defined by trails of $\mathrm{np} \mathrm{Fe}^{0}$ particles inside the Stardust sample (GEMS) suggests that the glassy spherule remained molten long enough for some internal mixing to occur but cooled fast enough to quench to a reduced glass (Ohtaki et al., 2019). A similar "swirl" pattern of sulfide blebs was found in a Tissint impact melt pocket (Fig. 5). The observations indicate that when $\mathrm{Fe}_{(1-x)} \mathrm{S}$ (pyrrhotite) is shock heated to high temperatures and pressures during impact, it is likely to produce clusters of $\mathrm{np} \mathrm{Fe}^{0}$ (metal) particles by isentropic cooling as well as dissolved sulfide that may in turn reach saturation and exsolve as sulfur-rich melts or precipitate a range of sulfide minerals. This is a different paragenesis from the S-rich blebs found in shergottite impact melts; the assemblage of $\mathrm{np} \mathrm{Fe}^{0}$ (metal) blebs has not been observed in any gas-rich impact melts studied in shergottites.

\section{What Happens When Ferric Sulfate Is Shock Melted at High Temperatures and Pressures by Meteoroid Impact on Mars?}

Ferric sulfate is found in Martian soils. If this material was gardened into the Martian regolith and was trapped in pores and voids at the site of the shergottiteforming impact(s), it would be shocked to high pressures (numerous shock indicators in shergottites are interpreted to require peak pressures of about $24 \mathrm{GPa}$; Beck et al., 2005; El Goresy et al., 2013; Gillet et al., 2007; Langenhorst \& Poirer, 2000; Sharp \& DeCarli, 2006; Shaw \& Walton, 2013) and anomalously high local temperatures $\left(\geq 2000^{\circ} \mathrm{C}\right)$ due to pore collapse. Thermodynamic calculations (Sheffer, 2007) show that, under these conditions, ferric sulfate dissolves into silicate-dominated impact melt and dissociates into ferric iron and sulfate ion. The cooling and expansion associated with release from the shock state promote reduction to ferrous iron and sulfite ion. These species may recombine to form iron sulfite (Hamann et al., 2018; Hörz et al., 2020). Or, depending on the intensity of the shock wave, the amount of vapor production, and the chemical environment, the sulfite may be further reduced to sulfide. Later, the cooling of sulfur-rich impact melt will cross the sulfide saturation point and exsolve droplets of immiscible FeS melt. These may form FeS blebs or may perhaps backreact with dissolved sulfite in the melt to form "mixed sulfite-sulfide" blebs in the quenched impact melts (Hamann et al., 2018; Hörz et al., 2020). There is insufficient reducing potential to take the $\mathrm{Fe}$ all the way down to $\mathrm{Fe}^{0}$. 


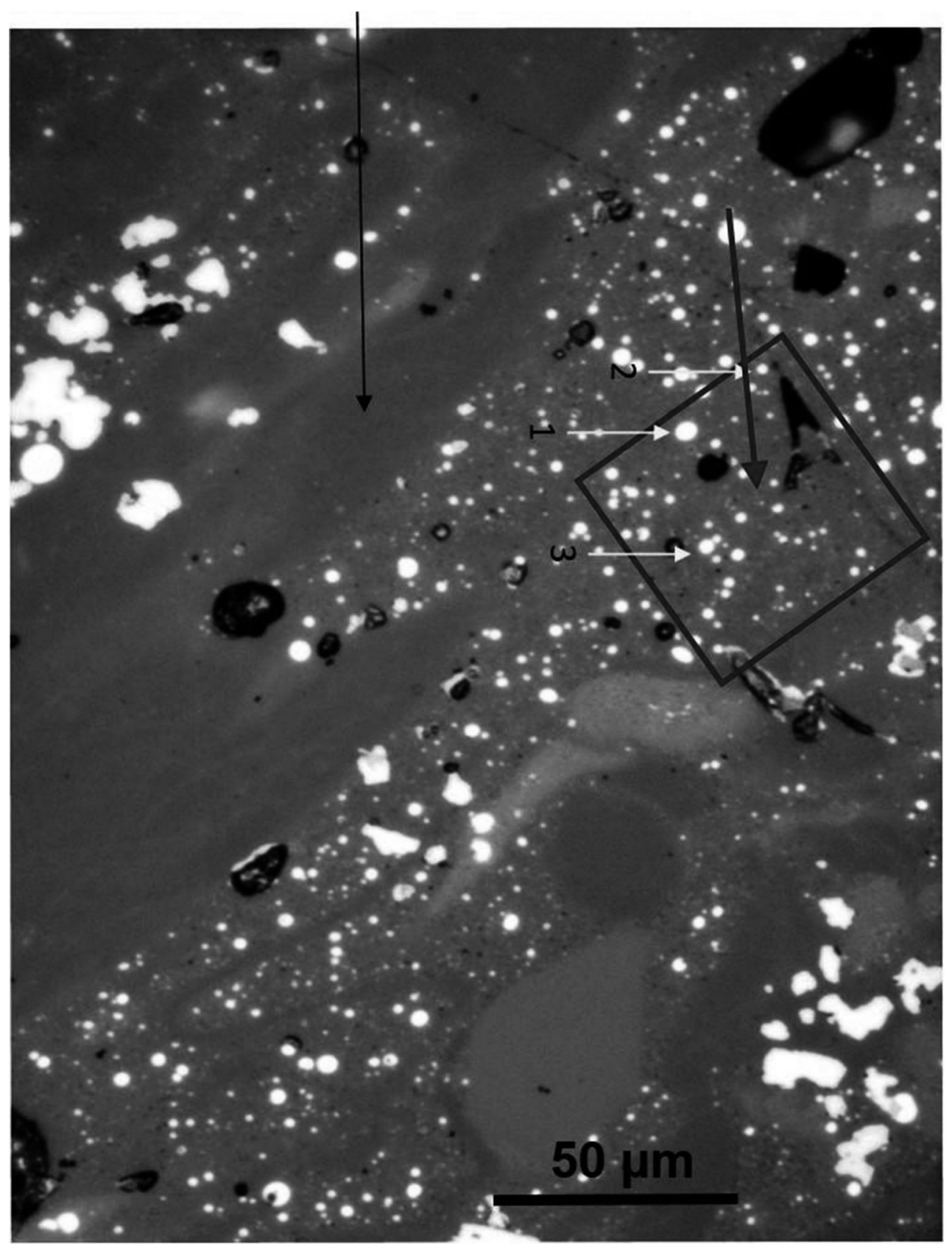

Fig. 6. Photomicrograph indicating the position of the line scan across IM\# 507. 507 area: yellow arrows point to S XANES analyzed spots. Blue box is the S map region (2idb1_0053.mda). Blue arrow is Fe XANES line scan (EET507_line_xanes.002). Point 17 of the line scan is near S spot 2. Spot 1 is EET507_sulfide1_xanes.001

We determined the iron oxidation state in impact melts \#506 and \#507 in EETA79001 using Fe K-edge micro-XANES (Rao et al., 2018; Sutton et al., 2008) (see Fig. 6). Each XANES acquisition was backgroundsubtracted and fitted to obtain an estimate of the mean oxidation state of the $\mathrm{Fe}$ atoms in the activation volume. An optical micrograph of the area studied in \#506 is shown in fig. 11A of Rao et al. (2018). Two line scans were performed; Fig. 6a shows the fitted mean $\mathrm{Fe}$ oxidation state as a function of position along line scan 1. The mean $\mathrm{Fe}$ oxidation state is relatively uniform from point to point, with an average for the line of $2.06 \pm 0.02$. Line scan 2 (not plotted here) appears very similar, with average mean $\mathrm{Fe}$ oxidation state of $2.11 \pm 0.03$. The simplest interpretation of these mean values is that $\mathrm{Fe}$ in glass \#506 exists as a mix of 
$\mathrm{Fe}^{2+}$ and $\mathrm{Fe}^{3+}$, with not more than a few percent $\mathrm{Fe}^{3+}$. Likewise, line scan results for mean $\mathrm{Fe}$ oxidation state along the line across IM \#507 are shown in Fig. 6b as indicated on the photomicrograph in Fig. 6c. Furthermore, the $\mathrm{Fe}$ oxidation state is uniform here within error and the average along the line is $2.07 \pm$ 0.03 . Notably, these XANES results agree well with the $\mathrm{Fe}^{2+} / \mathrm{Fe}^{3+}$ ratio determined in another large impact melt (\#27) in EETA79001 using Mössbauer spectroscopy by Solberg and Burns (1989). Although a mean Fe oxidation state above 2.0 does not explicitly demand the absence of metallic $\mathrm{Fe}$, especially in a rapidly quenched disequilibrium assemblage, in fact both IM pools \#506 and \#507 have been further examined at high resolution with FE-SEM instruments at JSC (Houston) as well as Max Planck Institute (Mainz, Germany) for Fe (metal) particles (Rao et al., 2018). Imaging results revealed no $\mathrm{Fe}^{0}$ (metal) grains in these impact melts.

\section{Relevance of the Shock Experimental Results to the Sulfur-Bearing Blebs Found in Large Impact Melts in Shergottites: A Model Perspective}

The model outline presented here is an extension of the earlier model discussed in Rao et al. (2018). Here, we recall a few salient features in that model. The shergottite source region (provenance) on Mars apparently consists of two different types of rock complexes. The first one hosts olivine-phyric rocks whose major igneous minerals are olivine, pyroxene, and feldspar from which shergottites such as Tissint, DaG 476, and EETA79001, Lith A, were launched by meteoroid impact. The second region consists of olivinefree pyroxene-phyric rocks (having feldspars and pyroxenes as major minerals), from which meteorites such as Shergotty, Zagami, Los Angeles, and EETA79001, Lith B, were derived. All the shergottite source rocks were apparently located at a relatively shallow depth (Artemieva \& Ivanov, 2004; Head et al., 2002; Melosh, 1984; Nyquist, 1983) but were pervasively buried or mantled by Martin soil and dust prior to impact launch.

The large overabundance of sulfur $\left(\sim 8 \%\right.$ as $\left.\mathrm{SO}_{3}\right)$ observed in Martian soils is usually attributed to chemical alteration caused by the interaction of sulfaterich acidic fluids with Martian rock and dust (Brückner et al., 2008; Clark et al., 2005; King \& McLennan, 2010; McAdam et al., 2014; Tosca et al., 2004) as discussed in Rao et al. (2018). In regions with low water-to-rock ratios, the $\mathrm{pH}$ of the solutions remained highly acidic $(\mathrm{pH} \sim 0-1)$ whereas, in other areas with higher water-to-rock ratios, the $\mathrm{pH}$ of these solutions became progressively less acidic ( $\mathrm{pH} \sim 3-5$; Banin et al.,
1997; Clark et al., 2005; Elwood Madden et al., 2004; Hurowitz et al., 2006; McSween et al., 2008; Settle, 1979).

We consider the case where highly acidic solutions ( $\mathrm{pH} \sim 0-1)$ percolated through rocks and soils near the shergottite provenance on Mars. These solutions initiate the rapid dissolution of soluble mineral phases, leaving behind relatively unaltered refractory minerals selectively unaffected (Hurowitz et al., 2006; King \& McSween, 2005; McCollom, Hynek, et al., 2013; McCollom, Robbins, et al., 2013; Tosca et al., 2004). The primary evolution of the fluid composition becomes dominated by the chemistry of the mineral phases most susceptible to acid dissolution (Hurowitz et al., 2006). In the case of the olivine-phyric rocks, the most soluble mineral is olivine, which contributes $\mathrm{Fe}$ and $\mathrm{Mg}$ to the solution. The solution is progressively neutralized by such mineral reactions. If the $\mathrm{pH}$ rises to between 1 and 2, Mg-sulfate will be highly soluble and can be transported in dissolved form from the reaction sites. $\mathrm{Fe}^{2+}$ may be oxidized to $\mathrm{Fe}^{3+}$ and precipitated as a highly insoluble ferric hydroxysulfate minerals such as jarosite. As a result, ferric sulfate becomes decoupled from $\mathrm{Mg}$-sulfate and other soluble phases (e.g., chlorides) in secondary mineral deposits. These findings are consistent with the demonstrated absence of $\mathrm{Mg}$ chlorides in impact melts \#506 and \#507 in EETA79001 studied by Rao et al. (2008). Furthermore, we note that Mg- and Ca-sulfates at high shock temperatures and pressures produce decomposition products (sulfide/sulfite or oxide), which do not yield immiscible fluids leading to bleb cluster formation.

As noted in Rao et al. (2018), the secondary sulfates thus produced on Mars were likely mobilized into cracks and voids of the host rock shergottites (prior to impact) by aeolian activity or soil erosion (Greeley et al., 2004; Meyer, 2012). Subsequently, when these deposits were shock heated to high temperatures and pressures during impact launching of the consolidated surface material assemblage, the constituent sulfates were decomposed and were reduced to sulfide/sulfite-mixes in large impact melts in shergottite melts due to isentropic cooling. The immiscible fluids thus resulted yield the observed bleb clusters upon quenching.

\section{SUMMARY AND CONCLUSIONS}

1. Although numerous studies have shown that shock compression and release can convert FeS pyrrhotite via fluid immiscibility to clusters of nanophase metallic $\mathrm{Fe}^{0}$ nanoparticles in impact melts, no such metallic particles were found during detailed 

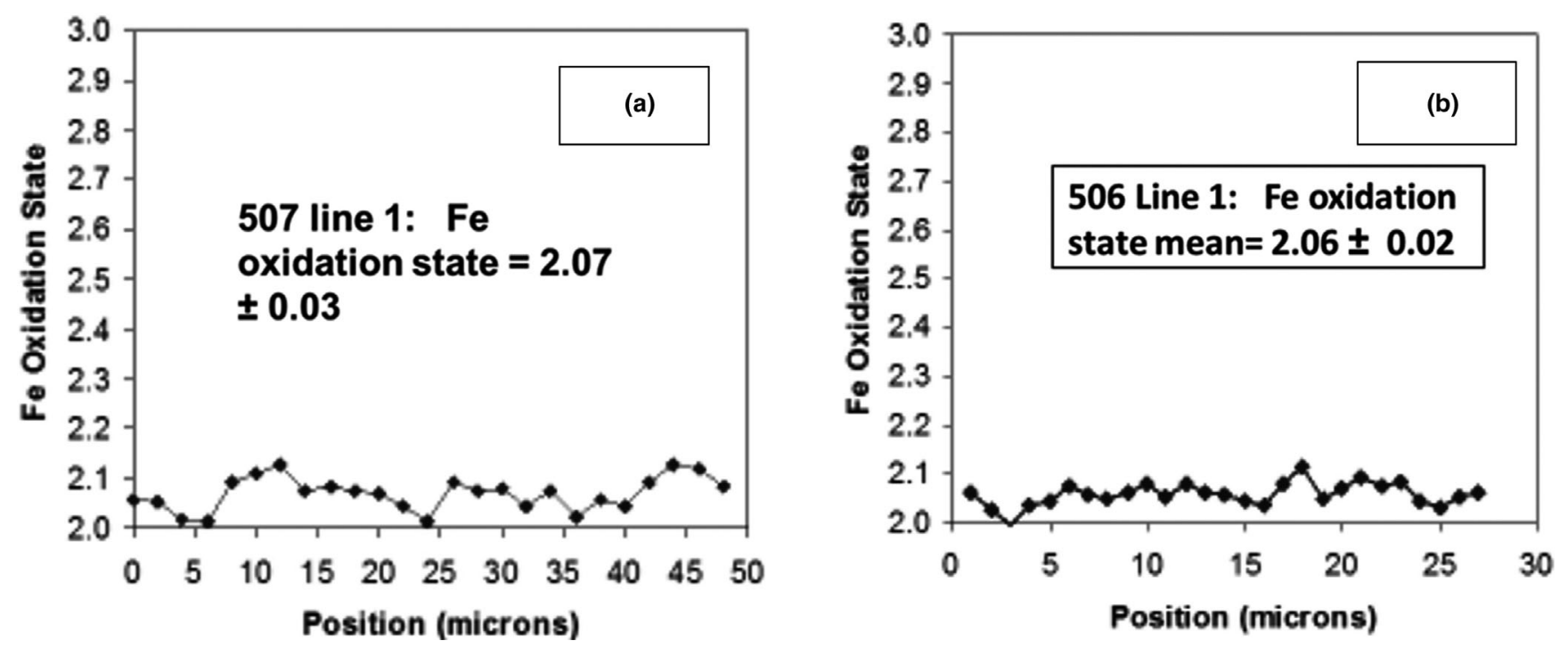

Fig. 7. Fe K-edge XANES studies of impact melts in EETA79001.a) The average Fe oxidation state for line scan 1 in IM \#506 is $2.06 \pm 0.02$ (Rao et al., 2018).b) The average Fe oxidation state for a line scan across IM\# 507 is $2.07 \pm 0.03$.

examination by FE-SEM and Fe K-edge XANES (Fig. 7) of impact melts from shergottites. This argues against the common igneous sulfides in shergottites being the source of sulfur for micrometer-sized bleb clusters found in these impact melts.

2. Shocking a porous mixture of ferric sulfate and CRB powder at $21 \mathrm{GPa}$ produced no sulfide blebs. Instead, amorphous regions marked by thermal contraction cracks were found that contain elevated concentrations of phosphorus, iron, and sulfur in a granitoid minimum melt-like composition suggesting incipient melting of the silicates, ferric sulfate, and apatite nuggets.

3. A similar target subjected to higher shock pressures, that is, $31 \mathrm{GPa}$, yielded numerous areas of quenched impact melt containing abundant clusters of micrometer-sized blebs of Fe-sulfide and Fe-sulfite mixtures. Although porosity in this experiment contained a small amount of $\mathrm{CO}$ gas, there was not enough $\mathrm{CO}$ in the capsule to act a significant reducing agent. Rather, we interpret this result as experimental evidence of the "reduction by isentropic cooling" hypothesis, which allows the melt phase to act as an open system and experience net reduction during vapor-present expansion from a high-temperature, high-pressure shock state. Ferric sulfate dissolves in the impact melt phase and then is reduced first to ferrous sulfite and subsequently, in part, to ferrous sulfide. Immiscibility of sulfite and sulfide melts in silicate melt then leads to dispersion of $\mu \mathrm{m}$-sized droplets dominated by both these components. We conclude that Fe-sulfate in porous, pyroxene-phyric Martian target rocks was most likely the source for sulfur in the metal-free $\mathrm{Fe}$-sulfite and $\mathrm{Fe}$-sulfide blebs observed by FE-SEM, S K-edge XANES (see Rao et al., 2018), and Fe K-edge XANES (Fig. 7) in shergottite impact melts such as \#507 in EETA79001, Lith B as well as \#784 in Los Angeles and DBS \#1 and \#2 in Shergotty. To conclusively address the issue of whether the small amount of $\mathrm{CO}$ initially present in the pore space acted as a trigger for the production of the observed sulfide bleb clusters in the recovered charge, we are planning to repeat the $31 \mathrm{GPa}$ experiment in a low-pressure $\mathrm{CO}_{2}$ atmosphere without $\mathrm{CO}$ presence.

4. We describe an outline of the extended model discussed in Rao et al. (2018) where it is noted that low $\mathrm{pH}$ acid-sulfate solutions presumably percolated through and reacted with olivine-phyric and pyroxene-phyric basaltic rocks in the shergottite source region producing secondary sulfates in a manner similar to that inferred from direct rover measurements at Meridiani, Gusev, and Gale craters. These sulfate assemblages were later mobilized into host rock voids and crevices by aeolian activity/soil erosion. During impact launching, they were shock melted at high temperature and pressures and the sulfate in the melts was reduced to sulfides by isentropic cooling (Melosh \& Artemieva, 2004; Sheffer \& Melosh, 2005). 
Acknowledgments - We thank Don Bogard, Fred Hörz, Mark Cintala, Abhijit Basu, and Jay Melosh for valuable discussions on different aspects related to this work. We thank Frank Cardenaes and Roland Montes for carrying out $21 \mathrm{GPa}$ shock experiment at EIL, Johnson Space Center (under the supervision of Mark Cintala). We thank Michael Long for carrying out the $31 \mathrm{GPa}$ experiment at the shock wave lab at Caltech which is supported by the NSF awards 1829277 and 1725349 to Paul Asimow. We thank Joachim Huth for FE SEM measurements on our PTS samples at MaxPlanck Institute fur Chemie, Mainz (Germany). This work is partly supported by NASA MFRP grant No. 08-0069 to Larry Nyquist at JSC. We thank Anita Rao of Qualcomm (San Diego, CA) for valuable computational assistance during this work. MNR is grateful to Alexander von Humboldt Stiftung (Germany) for partially supporting his presentation of the preliminary results obtained in this study at METSOC Meeting in Berlin in 2016. We are grateful to the Editor, Timothy Jull and the Associate Editor, Natalia Artemieva for efficient handling of our manuscript and to reviewers Christopher Hamann and Vincent Chevrier for valuable comments and suggestions that led to a significant improvement of the paper.

Data Availability Statement-Data openly available in a public repository that issues datasets with DOIs.

\section{Editorial Handling-Dr. Natalia Artemieva}

\section{REFERENCES}

Akaogi, M., Haraguchi, M., Nakanishi, K., Ajiro, H., and Kojitani, H. 2010. High-Pressure Phase Relations in the System $\mathrm{CaAl}_{4} \mathrm{Si}_{2} \mathrm{O}_{11}-\mathrm{NaAl}_{3} \mathrm{Si}_{3} \mathrm{O}_{11}$ with Implications for Na-Rich CAS Phase in the Shocked Martian Meteorites. Earth and Planetary Science Letters 289: 503-8.

Artemieva, N., and Ivanov, B. A. 2004. Launch of Martian Meteorites in Oblique Impacts. Icarus 171: 84-101.

Banin, A., Han, F. X., Kan, I., and Cicelsky, A. 1997. Acidic Volatiles and the Mars Soil. Journal of Geophysical Research 102: 13341-56.

Basu, A. 2005. Nanophase $\mathrm{Fe}^{0}$ in Lunar Soils. Journal of Earth System Science 114: 375-80.

Beck, P., Ferroir, T., and Gillet, P. 2007. Shock-Induced Compaction, Melting and Entrapment of Atmospheric Gases in Martian Meteorites. Geophysical Research Letters 34: L01203. https://doi.org/10.1029/2006GL028141.

Beck, P., Gillet, P. H., El Goresy, A., and Mostefaoui, S. 2005. Timescales of Shock Processes in Chondritic and Martian Meteorites. Nature 435: 1071-4. https://doi.org/ 10.1038 /nature03616.

Becker, R. H., and Pepin, R. O. 1984. The Case for a Martian Origin of Shergottites: Nitrogen and Noble Gases in EET 79001. Earth and Planetary Science Letters 69: 225-42.
Bibring, J. P., Langevin, Y., Mustard, J. F., Poulet, F., Arvidson, R., Gendrin, A., and Gondet, B. et al. 2007. Coupled Ferric Oxides and Sulfates on the Martian Surface. Science 317: 1206-10. https://doi.org/10.1126/ science.1144174.

Bogard, D. D., and Johnson, P. 1983. Martian Gases in an Antarctic Meteorite? Science 221: 651-4.

Bowling, T. J., Johnson, B. C., Wiggins, S. E., Walton, E. L., Melosh, H. J., and Sharp, T. G. 2020. Dwell Time at High Pressure of Meteorites During Impact Ejection from Mars. Icarus 343: 113689.

Brückner, J., Dreibus, G., Gellert, R., Squyres, S. W., Wãnke, H., Yen, A., and Zipfel, J. 2008. Mars Exploration Rovers: Chemical Composition by the APXS. In The Martian Surface-Composition, Mineralogy and Physical Properties, edited by J. F. Bell III, 58-102. Cambridge: Cambridge University Press.

Chen, G. Q., Tyburczy, J. A., and Ahrens, T. J. 1994. ShockInduced Devolatilization of Calcium-Sulfate and Implications for K-T Extinctions. Earth and Planetary Science Letters 128: 615-28.

Chen, M., Sharp, T. G., El Goresy, A., Wopenka, B., and Xie, X. 1996. The Majorite-Pyrope + Magnesiowustite Assemblage: Constraints on the Shock History of Chondrites. Science 271: 1570-3.

Clark, B. C., Morris, R. V., McLennan, S. M., Gellert, R., Jolliff, B., Knoll, A. H., Squyres, S. W. et al. 2005. Chemistry and Mineralogy of Outcrops at Meridiani Planum. Earth and Planetary Science Letters 240: 73-94.

Davies, E. J., Carter, P. J., Root, S., Kraus, R. G., Spaulding, D. K., Stewart, S. T., and Jacobsen, S. B. 2020. Silicate Melting and Vaporization During Rocky Planet Formation. Journal of Geophysical Research: Planets 125: e2019JE006227. https://doi.org/10.1029/2019JE006227.

El Goresy, A., Gillet, P. H., Miyahara, M., Ohtani, E., Ozawa, S., Beck, P., and Montagnac, G. 2013. ShockInduced Deformation of Shergottites: Shock Pressures and Perturbations of Magmatic Ages on Mars. Geochimica et Cosmochimica Acta 101: 233-62.

Elwood Madden, M. E., Bodnar, R. J., and Rimstidt, J. D. 2004. Jarosite as an Indicator of Water-Limited Chemical Weathering on Mars. Nature 431: 821-3.

Fleet, M. E., Liu, X., Harms, S. L., and King, P. L. 2005. Sulfur K-Edge XANES Spectroscopy: Chemical State and Content of Sulfur in Silicate Glasses. Canadian Mineralogist 43: 1605-18.

Gattacceca, J., Rochette, P., Cournede, C., Hewins, R., Sautter, V., Scorzelli, R., Uehara, M., and Zanda, B. 2013. Opaque Minerals, Magnetic Properties and Paleomagnetism of the Tissint Martian Meteorite. Meteoritics \& Planetary Science 48: 1919-36.

Gellert, R., Rieder, R., Anderson, R. C., Brückner, J., Clark, B. C., Dreibus, G., Economou, T. et al. 2004. Chemistry of Rocks and Soils in Gusev Crater from the AlphaParticle X-Ray Spectrometer. Science 305: 829-32.

Gillet, P., Chen, M., Dubrovinsky, L., and El Goresy, A. 2000. Natural $\mathrm{NaAlSi}_{3} \mathrm{O}_{8}$-Hollandite in the Shocked Sixiangkou Meteorite. Science 287: 1633-6.

Gillet, P. and El Goresy, A. 2013. Shock Events in the Solar System: The Message from Minerals in Terrestrial Planets and Asteroids. Annual Review of Earth and Planetary Sciences 41: 257-85.

Gillet, P., El Goresy, A., Beck, P., and Chen, M. 2007. HighPressure Mineral Assemblages in Shocked Meteorites and 
Shocked Terrestrial Rocks: Mechanisms of Phase Transformations and Constraints to Pressure and Temperature Histories. In Advances in High Pressure Mineralogy, edited by E. Ohtani. Geological Society of America, Special Paper 421: 57-82.

Greeley, R., Squyres, S. W., Arvidson, R. E., Bartlett, P., Bell, J. F., Blaney, D., Cabrol, N. A., Farmer, J., Farrand, B., and Golombek, M. P. 2004. Wind-Related Processes Detected by the Spirit Rover at the Gusev Crater Mars. Science 305: 810-3. https://doi.org/10.1126/science. 1100108.

Gupta, S. C., Ahrens, T. J., and Yang, W. 2001. ShockInduced Vaporization of Anhydrite and Global Cooling from the K/T Impact. Earth and Planetary Science Letters 188: 99-412.

Hamann, C., Fazio, A., Ebert, M., Hecht, L., Wirth, R., Folco, L., Deutsch, A., and Reimold, W. U. 2018. Silicate Liquid Immiscibility in Impact Melts. Meteoritics \& Planetary Science 53: 1594-632. https://doi.org/10.1111/ maps. 12907.

Head, E., Lanzirotti, A., Newville, M., and Sutton, S. R. 2018. Vanadium, Sulfur and Iron Valencies in Melt Inclusions as a Window into Magmatic Processes: A Case Study at Nyanuragira Volcano, Africa. Geochimica et Cosmochimica Acta 226: 149-73. https://doi.org/10.1016/j. gca.2018.01.033.

Head, J. N., Melosh, H. J., and Ivanov, B. A. 2002. Martian Meteorite Launch: High Speed Ejecta from Small Craters. Science 298: 1752-6.

Hidaka, H., Yoneda, S., and Nishiizumi, K. 2009. CosmicRay Exposure Histories of Martian Meteorites Studied from Neutron Capture Reactions of Sm and Gd Isotopes. Earth and Planetary Science Letters 288: 564-71.

Hörz, F., Cintala, M. J., Thomas-Keprta, K. L., Ross, D. K., and Clemett, S. J. 2020. Unconfined Shock Experiments: A Pilot Study into the Sock-Induced Melting and Devolatilization of Calcite. Meteoritics \& Planetary Science 55: 102-29.

Hurowitz, J. A., McLennan, S. M., Tosca, N. J., Arvidson, R. E., Michalski, J. R., Ming, D. W., Schroder, C., and Squyres, S. W. 2006. In Situ and Experimental Evidence for Acid Weathering of Rocks and Soils on Mars. Journal of Geophysical Research 111: E02S19. https://doi.org/10. 1029/2005JE002515.

Ishii, A. H., Bradley, J. P., Dai, Z. R., Chi, M., Kearsley, A. T., Burchell, M. J., Browning, N. D., and Molster, F. 2008. Comparison of Comet 81P/Wild 2 Dust with Interplanetary Dust from Comets. Science 319: 447-50.

Ivanov, B. A., and Deutsch, A. 2002. The Phase Diagram of $\mathrm{CaCO}_{3}$ in Relation to Shock Compression and Decomposition. Physics of the Earth and Planetary Interiors 129: 131-43.

Keller, L. P., and Berger, E. L. 2014. A Transmission Electron Microscope Study of Itokawa Regolith Grains. Earth, Planets and Space 66: 1-7.

Keller, L. P., and McKay, D. S. 1997. The Nature and Origin of Rims on Lunar Soil Grains. Geochimica et Cosmochimica Acta 61: 2331-41.

King, P. L., and McLennan, S. M. 2010. Sulfur on Mars. Elements 6: 107-12.

King, P. L., and McSween, H. Y. 2005. Effects of $\mathrm{H}_{2} \mathrm{O}, \mathrm{pH}$, and Oxidation State on the Stability of Fe Minerals on Mars. Journal of Geophysical Research 110: E12S10. https://doi.org/10.1029/2005JE002482.
Langenhorst, F., and Poirier, J. P. 2000. Anatomy of Black Veins in Zagami: Clues to the Formation of High-Pressure Phases. Earth and Planetary Science Letters 184: 37-55.

Lorand, J. P., Chevrier, V., and Sautter, V. 2005. Sulfide Mineralogy and Redox Conditions in Some Shergottites. Meteoritics \& Planetary Science 40: 1257-72.

Malavergne, V., Guyot, F., Benzerara, K., and Martinez, I. 2001. Description of New Shock-Induced Phases in the Shergotty, Zagami, Nakhla and Chassigny Meteorites. Meteoritics \& Planetary Science 36: 1297-305.

McAdam, A. C., Franz, H. B., Sutter, B., Archer, P. D., Freissinet, C., Eigenbrode, J. L., Ming, D. W. et al. 2014. Sulfur-Bearing Phases Detected by Evolved Gas Analysis of the Rocknest Aeolian Deposit, Gale Crater, Mars. Journal of Geophysical Research: Planets 119: 37393.

McCollom, T. M., Hynek, B. M., Rogers, K., Moskowitz, B., and Berquó, T. S. 2013. Chemical and Mineralogical Trends During Acid-Sulfate Alteration of Pyroclastic Basalt at Cerro Negro Volcano and Implications for Early Mars. Journal of Geophysical Research: Planets 118: 171951.

McCollom, T. M., Robbins, M., Moskowitz, B., Berquó, T. S., Jöns, N., and Hynek, B. M. 2013. Experimental Study of Acid-Sulfate Alteration of Basalt and Implications for Sulfate Deposits on Mars. Journal of Geophysical Research: Planets 118: 577-614.

McLennan, S. M. 2012. Geochemistry of Sedimentary Processes on Mars. In Mars Sedimentology, edited by J. P. Grotzinger and R. E. Milliken, 119-38. New York: SEPM Special Publication.

McSween Jr., H. Y., and Jarosewich, E. 1983. Petrogenesis of the Elephant Moraine A79001 Meteorite: Multiple Magma Pulses on the Shergottite Parent Body. Geochimica et Cosmochimica Acta 47: 1501-13.

McSween, H. Y., Ruff, S. W., Morris, R. V., Gellert, R., Klingelhoffer, G., Christensen, P. R., McCoy, T. J. et al. 2008. Mineralogy of Volcanic Rocks in Gusev Crater, Mars: Reconciling Mossbauer, Alpha Particle X-Ray Spectrometer and Miniature Thermal Emission Spectrometer Spectra. Journal of Geophysical Research 113: E06S04.

Melosh, H. J. 1984. Impact Ejection, Spallation and the Origin of Meteorites. Icarus 59: 234-60.

Melosh, H. J., and Artemieva, N. 2004. How Does Tektite Glass Lose its Water? (abstract \#1723). 35th Lunar and Planetary Science Conference. CD-ROM.

Meyer, C. 2012. Mars Meteorite Compendium. Report 27672, 1-175. Houston, Texas: Johnson Space Center.

Miyahara, M., Ohtani, E., Ozawa, S., Kimura, M., El Goresy, A., Sakai, T., Nagase, T., Hiraga, K., Hirao, N., and Ohishi, Y. 2011. Natural Dissociation of Olivine to $(\mathrm{Mg}$, $\mathrm{Fe}) \mathrm{SiO}_{3}$ Perovskite and Magnesiowüstite in a Shocked Martian Meteorite. Proceedings of the National Academy of Sciences 108: 5999-6003.

Morris, R. V., Klingelhoffer, G., Schroder, C., Rodionov, D. S., Yen, A., Ming, D. W., \& De Souza Jr., P. A. 2006. Mossbauer Mineralogy of Rock, Soil and Dust at Gusev Crater Mars: Spirit's Journey Through Weakly Altered Olivine Basalt on the Plains and Pervasively Altered Basalt in the Columbia Hills. Journal of Geophysical Research 111: E02S13. https://doi.org/10.1029/2005JE002584.

Newvile, M., Sutton, S. R., Rivers, M., and Eng, P. 1998. Micro-Beam X-Ray Absorption and Fluorescence 
Spectroscopies at GSECARS: APS Beam Line 13ID. Journal of Synchrotron Radiation 6: 353-5.

Noguchi, T., Kimura, M., Hashimoto, T., Konno, M., Nakamura, T., Zolensky, M. E., Okazaki, R. et al. 2014. Space Weathered Rims Found on the Surfaces of Itokawa Dust Particles. Meteoritics \& Planetary Science 49: 188214.

Nyquist, L. E. 1983. Do Oblique Impacts Produce Martian Meteorites? Proceedings, 13th Lunar and Planetary Science Conference. Journal of Geophysical Research 88: A785-98.

Ohtaki, K. K., Bradley, J. P., Gillis-Davis, J. J., Taylor, G. J., and Ishii, H. A. 2019. Formation of Iron-Rich NanoParticles Within Glassy Silicate Spherules in Lunar Soil (abstract \#2156). 50th Lunar and Planetary Science Conference. CD-ROM.

Rao, M. N., Bogard, D. D., Nyquist, L. E., McKay, D. S., and Masarik, J. 2002. Neutron Capture Isotopes in the Martian Regolith and Implications for Martian Atmospheric Noble Gases. Icarus 156: 352-72.

Rao, M. N., Borg, L. E., McKay, D. S., and Wentworth, S. J. 1999. Martian Soil Component in Impact Glasses in a Martian Meteorite. Geophysical Research Letters 26: 3265-8.

Rao, M. N., Nyquist, L. E., Bogard, D. D., Garrison, D. H., Sutton, S. R., Michel, R., Reedy, R. C., and Leya, I. 2011. Isotopic Evidence for a Martian Regolith Component in Shergottite Meteorites. Journal of Geophysical Research 116: E08006. https://doi.org/10.1029/2010JE003764.

Rao, M. N., Nyquist, L. E., Ross, D. K., Sutton, S. R., Hoppe, P., Shih, C.-Y., Wentworth, S. J., and Garrison, D. H. 2018. Signatures of Martian Regolith Components Entrained in Some Impact-Melt Glasses in Shergottites. Meteoritics \& Planetary Science 53: 2558-82. https://doi. org/10.1111/maps13177.

Rao, M. N., Nyquist, L. E., Ross, D. K., and Wentworth, S. J. 2019. Acid-Sulfate Weathering Environment at the Shergottite Provenance on Mars (abstract \#1950). 50th Lunar and Planetary Science Conference. CD-ROM.

Rao, M. N., Nyquist, L. E., Wentworth, S. J., Sutton, S. R., and Garrison, D. H. 2008. The Nature of Martian Fluids Based on Mobile Element Studies in Salt-Assemblages from Martian Meteorites. Journal of Geophysical Research 113: https://doi.org/10.1029/2007JE002958.

Ross, D. K., Ito, M., Hervig, R., Rao, M. N., and Nyquist, L. E. 2011. Recognizing the Effects of Terrestrial Contamination on $\mathrm{D} / \mathrm{H}$ Ratios in Shergottite Phosphates (Abstract \#1920). 42nd Lunar and Planetary Science Conference. CD-ROM.

Schaal, R. B., Hörz, F., Thompson, T. D., and Bauer, J. F. 1979. Shock Metamorphism of Granulated Lunar Basalt. Proceedings, 10th Lunar and Planetary Science Conference, pp. 2547-71.

Schrader, C. M., Cohen, B. A., Donovan, J. J., and Vicenzi, E. P. 2016. Ni/S/Cl systematics and the Origin of ImpactMelt Glasses in Martian Meteorite Elephant Moraine 79001. Meteoritics \& Planetary Science 51: 663-80.

See, T. H., Horz, F., and Cintala, M. J. 2001. Experimentally Produced Shock Melts in Impact-Comminuted Powders of an L6 Ordinary Chondrite (abstract \#1807). 32nd Lunar and Planetary Science Conference. CD-ROM.
Settle, M. 1979. Formation and Deposition of Volcanic Sulfate Aerosols on Mars. Journal of Geophysical Research 84: 8343-54.

Sharp, T. G., and DeCarli, P. G. 2006. Shock Effects in Meteorites. In Meteorites and the Early Solar System II, edited by H. Y. McSween and D. S. Lauretta, 653-77. Tucson, Arizona: The University of Arizona Press.

Shaw, C. S. J., and Walton, E. 2013. Thermal Modelling of Shock Melts in Martian Meteorites: Implications for Preserving Martian Atmospheric Signatures and Crystallization of High-Pressure Minerals from Shock Melts. Meteoritics \& Planetary Science 48: 758-70.

Sheffer, A. 2007. Chemical Reduction of Silicates by Meteorite Impacts and Lightning Strikes. PhD Dissertation, Department of Planetary Sciences, University of Arizona, Tucson, Arizona.

Sheffer, A., Dyar, M. D., and Sklute, E. C. 2006. Lightning Strike Glasses as an Analog for Impact Glasses: ${ }^{57} \mathrm{Fe}$ Mossbauer Spectroscopy of Fulgurites (abstract \#2009). 35th Lunar and Planetary Science Conference. CD-ROM.

Sheffer, A., and Melosh, H. J. 2005. Why Moldavites Are Reduced (abstract \#1468). 36th Lunar and Planetary Science Conference. CD-ROM.

Solberg, T. C., and Burns, R. G. 1989. Mössbauer Spectral Study of Weathered Antarctic and SNC Meteorites. Proceedings, 19th Lunar and Planetary Science Conference, pp. 313-22.

Sutton, S. R., Rao, M. N., and Nyquist, L. E. 2008. Sulfur and Iron Speciation in Gas-Rich Impact-Melt Glasses from Basaltic Shergottites Determined by microXANES (abstract \#1961). 39th Lunar and Planetary Science Conference. CD-ROM.

Swindle, T. D., Caffee, M. W., and Hohenberg, C. M. 1986. Xenon and Other Noble Gases in Shergottites. Geochimica et Cosmochimica Acta 50: 1001-15.

Tomioka, N., and Miyahara, M. 2017. High Pressure Minerals in Shocked Meteorites. Meteoritics \& Planetary Science 52: 2017-39.

Tosca, N. J., McLennan, S. M., Lindsley, D. H., and Schoonen, M. A. A. 2004. Acid-Sulfate Weathering of Synthetic Martian Basalt: The Acid Fog Model Revisited. Journal of Geophysical Research 109: E05003. https://doi. org/10.1029/2003JE002218.

Wentworth, S. J., Gibson, E. K., Velbel, M. A., and McKay, D. S. 2005. Antarctic Dry Valleys and Indigenous Weathering in Mars Meteorites: Implications for Water and Life on Mars. Icarus 174: 383-95.

Wiens, R. C. 1988. Noble Gases Released by Vacuum Crushing of EET79001 Glass. Earth and Planetary Science Letters 91: 55-65.

Wilke, M., Jugo, P. J., Klimm, K., Susini, J., Botcharnikov, R., Kohn, S. C., and Janousch, M. 2008. The Origin of S4+ Detected in Silicate Glasses by XANES. American Mineralogist 93: 235-40.

Yagi, T., Suzuki, T., and Akaogi, M. 1994. High Pressure Transitions in the System $\mathrm{KAlSi}_{3} \mathrm{O}_{8} \mathrm{NaAlSi}_{3} \mathrm{O}_{8}$. Physics and Chemistry of Minerals 21: 12-7.

Zhang, F., and Sekine, T. 2007. Impact-Shock Behavior of Mg-and Ca-Sulfates and Their Hydrates. Geochimica et Cosmochimica Acta 71: 4125-33. 